\title{
Peri-operative amino acid administration and the metabolic response to surgery
}

\author{
Eva Selldén \\ Department of Anaesthesia and Intensive Care, Karolinska Hospital, S-171 76 Stockholm, Sweden
}

\begin{abstract}
General anaesthesia causes hypothermia due to decreased metabolic rate and impaired thermoregulation. Many warming devices are in use to prevent heat loss, but little attention has been paid to stimulating the body's own heat generation. All nutrients raise energy expenditure, and the highest thermic effect is ascribed to amino acids and proteins, $30-40 \%$ in the awake state. Amino acids infused during general anaesthesia exert a thermic effect that is enhanced compared with that in the awake state. At awakening from anaesthesia, post-operative hypothermia may be prevented without shivering. The tissues involved and the mechanisms by which nutrients stimulate heat production are still not completely understood. However, these findings support the existence of an inhibitory action normally exerted by central thermosensors, in order to maintain oxidative metabolism within certain limits, to prevent hyperthermia. During anaesthesia central thermosensors are silenced and, hence, amino acid thermogenesis is exaggerated. The amino acidinduced heat generation during anaesthesia predominantly occurs in extra-splanchnic tissues, most probably in skeletal muscle. It may reflect an increased protein turnover, as both protein breakdown and synthesis are energy-consuming processes known to generate heat. Possibly, amino acid infusion provides substrates, otherwise mobilized from the body's own tissues, needed for wound healing and immunological function. However, other cellular mechanisms may also contribute to this non-shivering thermogenesis.
\end{abstract}

Anaesthesia: Metabolism: Amino acid infusion: Hypothermia: Thermogenesis

\section{Anaesthesia: a hypometabolic and hypothermic state}

Anaesthesia and surgery are frequently accompanied by hypothermia. Until recently, $60 \%$ of adult surgical patients entered the recovery room with a core temperature $1-1 \cdot 5^{\circ} \mathrm{C}$ below normal (Vaughan et al. 1981). This thermal imbalance, typically developing quickly after anaesthesia induction, results from decreased heat production, increased heat loss and impaired hypothalamic thermoregulation. However, available data suggest that the reduction in metabolism and heat production by 30-50 \% caused by anaesthetic agents (Brismar et al. 1982) remains the most important factor for hypothermia development. It is not fully understood which organs account for the depressed metabolism during anaesthesia. Studies in animals have shown that a major component may be related to a decrease in myocardial $\mathrm{O}_{2}$ consumption due to reduced cardiac work (Theye \& Michenfelder, 1975); however, other tissues also contribute. Moreover, it is not known which metabolic processes are inhibited or depressed during anaesthesia.
During anaesthesia, thermogenesis is also impaired due to inhibition of shivering by muscle relaxants. However, metabolic heat production due to shivering is surprisingly ineffective, as only 10-11\% of the heat produced contributes to a rise in body temperature (Horwath et al. 1956). Shivering is also rarely seen during general anaesthesia in non-paralysed patients, which suggests that general anaesthesia decreases the shivering threshold far more than the threshold for the initiation of vasoconstriction. In addition, the mechanisms of non-shivering heat generation in brown adipose tissue (in infants) are suppressed during inhalational anaesthesia (Ohlson et al. 1994).

Theoretically, heat may also be generated by the release of thyroxine from the thyroid gland, via thyrotropinreleasing hormone and thyroid-stimulating hormone, as a response to cooling of arterial blood in the preoptic area of the hypothalamus. This process results in an increased rate of cellular metabolism in most cells of the body, by increasing the size and number of mitochondria, as well as their total membrane surface area. Thus, ATP formation is 
accelerated. However, this process does not take place immediately. It takes several weeks for the thyroid gland to become hypertrophic and to reach its new level of thyroxine secretion, and therefore it is not a relevant mechanism during acute trauma and anaesthesia.

Factors contributing to the development of hypothermia during surgery are increased heat losses, mainly by radiation, convection and evaporation in adults, combined with conductive heat losses in younger children. This process is facilitated by reduced sympathetic tone and peripheral vasodilation caused by anaesthetic agents, with a subsequent core-to-periphery heat redistribution. Accordingly, if general and regional anaesthesia are combined, there is an additive effect on both the duration and magnitude of hypothermia (Joris et al. 1994).

\section{Why is hypothermia during surgery a clinical problem?}

A moderate decrease in temperature of brief duration is usually well tolerated by human subjects, and may be of substantial benefit in situations of ischaemic and hypoxic insults occurring during neurosurgery or carotid artery surgery (Leslie \& Solly, 1995). Generally, protection is thought to result from the reduced $\mathrm{O}_{2}$ consumption ( $7 \%$ for every $1^{\circ} \mathrm{C}$ decrease in body temperature); however, other mechanisms may contribute.

Hypothermia is, however, associated with potentially severe complications in most organ systems in the body. It is now well documented that even mild hypothermia reduces resistance to surgical wound infection, disturbs blood coagulation with increased blood loss, increases the risk of morbid cardiac events, delays drug metabolism due to impaired hepatic function and prolongs hospital stay. Postoperative adrenergic activation during shivering may be substantial (Frank et al. 1995), and several patients report that in the recovery room discomfort of shivering and sensation of cold are worse than surgical pain (Kurz et al. 1995).

\section{Prevention of hypothermia}

Improved thermal care in the peri-operative period has attracted growing interest, mainly focused on the development of efficient warming devices to prevent heat loss. Little attention has been paid to preventing the development of anaesthesia-induced hypothermia by stimulating the generation of heat.

It is well known that all nutrients raise resting energy expenditure by the mechanism(s) of nutrient-induced thermogenesis (NIT). In a series of studies we have demonstrated an increased thermic effect of amino acids infused during anaesthesia, which may be used to prevent anaesthesia-induced hypothermia and hypometabolism.

\section{Nutrient-induced thermogenesis}

NIT is the increase in oxidative metabolism and, hence, heat production that occurs in response to nutrient administration (Jéquier, 1986). This postprandial rise in energy expenditure starts immediately after a meal, reaches a maximum after $1-2 \mathrm{~h}$ and then declines after 5-7 $\mathrm{h}$. The tissues involved and mechanisms by which the nutrients stimulate heat production are still not completely understood.

The concept of NIT was first reported in the late 18th century by Lavoisier, who established the relationship between gas exchange and heat production in animals. Together with Séguin he also studied the pulmonary uptake of 'air vitale', later known as $\mathrm{O}_{2}$, in man, and found that the respiratory consumption of $\mathrm{O}_{2}$ varied with physical activity, room temperature and food ingestion. The first systematic examination of increased thermogenesis in response to nutrients was performed 100 years later by Max Rubner (1902). He measured the increase in $\mathrm{O}_{2}$ consumption and heat production in the dog by indirect calorimetry both during fasting and feeding with meat. It was described as 'Die Spezifische Dynamische Wirkung der Nahrungsstoffe (the specific dynamic effect of food)'. In English literature it was translated into 'the specific dynamic action', and several years later the terms 'nutrient-induced thermogenesis' and 'thermic effect of food' were both established.

In healthy normal-weight adults the thermogenic action exerted by a specific nutrient relates closely to its energy content (Jéquier, 1986). However, different nutrients have different thermic effects. The thermic effect is defined as the increase in whole-body energy expenditure as a percentage of the metabolizable energy content of the nutrient given. Proteins or mixtures of amino acids exert the highest thermic effect (30-40\%); the thermic effect of carbohydrate is moderate (6-9\%) and that of fat is hardly measurable (0-2\%). As a result of these proportions, the protein-induced thermogenesis quantitatively dominates the total thermogenic response to most mixed diets. The magnitude of NIT may change from normal in certain pathophysiological conditions. Thus, obesity and diabetes type 2 with insulin resistance are often associated with a reduced NIT, while an augmented NIT may occur with metabolic disorders accompanied by catabolism, e.g. Crohn's disease.

Insufficient nutrient supply is accompanied by a gradual decrease in basal energy expenditure and, finally, in body temperature.

\section{Nutrient-induced thermogenesis: obligatory and/or facultative thermogenesis?}

The total NIT exceeds the calculated metabolic costs of digestion, absorption, processing and storage of the nutrients. Thus, traditionally, the NIT has been divided into an 'obligatory part' related to those metabolic costs, and a 'facultative' component, reflecting the energy expended in excess of the processing requirements. Neumann (1902) coined the term 'Luxusconsumption' for the facultative component of thermogenesis.

Non-shivering, or 'facultative', thermogenesis most probably represents a collection of mechanisms to generate heat. Hitherto, it has been attributed to brown adipose tissue in rodents and newborn babies $<7-8$ months of age. The macroscopic brown colouration of this adipose tissue is due to its enormous density of mitochondria. Brown fat has a rich sympathetic innervation, with $\beta_{3}$-adrenergic receptors on nerve endings terminating in both cells and blood vessels. The metabolic mechanism, regulated by noradrenaline, is to uncouple oxidative phosphorylation via an 
uncoupling protein (UCP), UCP 1, so that excess substrates are oxidized and energy is released in the form of heat without formation of ATP (Nedergaard \& Cannon, 1998).

However, later investigations have suggested nonshivering thermogenesis also in skeletal muscle of animals not having brown fat. One suggested mechanism for this increase in $\mathrm{O}_{2}$ uptake, and hence heat production, is that it is due to a site-specific action in vasoconstrictors that switch nutritional flows on and off in skeletal muscle. An alternative mechanism might be a site-specific second messenger that induces a temporary mitochondrial uncoupling in skeletal muscle (Clark et al. 1995). Furthermore, the UCP (UCP 1) responsible for the thermogenesis in brown adipose tissue has now been identified as a member of a UCP family of mitochondrial transporter proteins, existing in various tissues and implicated in thermoregulatory heat production. Hitherto UCP 1 (in brown fat), UCP 2 (in several tissues), UCP 3 (mainly in skeletal muscle) and UCP 4 (in the brain) have been described (Jezek \& Garlid, 1998; Mao et al. 1999). Recent research has shown rapid advances in the understanding of the molecular regulation of energy expenditure in mitochondria (Lowell \& Spiegelman, 2000). Clearly, the UCP family of proteins, whose physiological role has still not been fully elucidated, may play a role in muscle non-shivering thermogenesis.

Obviously, the involvement of the sympathetic nervous system in NIT has attracted scientific interest. This interest is based on the fact that increased sympatho-adrenal activity per se increases the whole-body metabolic rate. Thus, NIT typically was claimed to occur in skeletal muscle as a result of increased sympathetic activity (Landsberg \& Young, 1978). This view was supported by findings of increased plasma catecholamines and an increased peripheral sympathetic nerve activity associated with carbohydrate intake (Welle et al. 1981; Berne et al. 1989). However, carbohydrates induce only a weak thermogenesis. In contrast, the marked protein- and amino acid-induced thermogenesis is not accompanied by increased plasma catecholamines (Welle et al. 1981), although later studies showed a small increase in peripheral sympathetic nerve activity after protein intake (Fagius \& Berne, 1994); the quantitative importance of this finding may, however, be questioned.

Moreover, if a substantial part of the NIT depended on central sympathetic activation, patients with complete cervical spinal cord injury, lacking supra-spinal control of their sympatho-adrenal system, would not be able to produce heat after a meal. The thermic effect after a mixed meal, oral glucose and intravenous amino acids was, however, found to be normal or supranormal in the patient with spinal injury, whose body temperature increased significantly $(\mathrm{P}<0.05$; during amino acid infusion) with no accompanying rise in sympatho-adrenal activity (Aksnes et al. 1993, 1994, 1995). These results suggested that NIT is not dependent on efferent stimulation from the brain. The heat is evidently produced in the periphery.

Overall, there is no conclusive support for the suggestion that in man central sympatho-adrenal activation plays a quantitatively important role in NIT under physiological conditions. Even the existence of a 'Luxusconsumption' has been questioned, as the substantially increased central sympathetic activation after carbohydrate intake fails to affect $\mathrm{O}_{2}$ uptake. Instead, it is suggested that the entire NIT might be accounted for by the metabolic costs of nutrient processing and the costs of the mechanisms necessary for the control of nutrient processing (Newsholme et al. 1992). Thus, there may be no space for 'facultative thermogenesis'. Nevertheless, it is increasingly evident that the physiological mechanisms underlying NIT differ between nutrients (Brundin, 1997, 1998).

\section{Nutrient-induced thermogenesis during anaesthesia}

Traditionally, nutrients are seldom given before or during surgery, which results in starvation, with a reduced metabolic rate. The general opinion is that nutrients cannot be used during anaesthesia and surgery. Hence, nutrients have not been considered to be needed in the peri-operative period. However, recent studies have shown that a carbohydrate drink administered just before surgery attenuates post-operative insulin resistance by $50 \%$ and thus improves patient recovery, as shown by a shorter hospital stay (Thorell et al. 1999). This finding means that the preoperative carbohydrate drink reduces insulin resistance and initiates metabolic processes associated with energy storage (hence, perhaps heat production). Unfortunately, body temperature was not measured in these studies. Another explanation for the restrictive attitude towards nutrition during surgery may be the decreased protein synthesis in skeletal muscle, which is known to be unaffected by total parenteral nutrition (Essén et al. 1993) not containing glutamine (Hammarqvist et al. 1989).

Consequently, it was of interest to investigate amino acid administration during anaesthesia and surgery. First, NIT was examined during general anaesthesia and muscle relaxation, and this study was followed by investigations into heat production from nutrient administration during surgical trauma.

\section{Amino acid infusion and thermal balance during anaesthesia}

In a series of studies a balanced amino acid solution was given intravenously, at a rate of $240 \mathrm{~kJ} / \mathrm{h}$, to patients subjected to abdominal surgery. Core temperature and whole-body $\mathrm{O}_{2}$ uptake were measured before, during and after general inhalational anaesthesia. The results were compared with data from a control group of patients subjected to similar surgical procedures. We found that the decrease in body temperature was more pronounced in the control patients than in patients who received the amino acid solution, and remained so throughout anaesthesia. Simultaneously, $\mathrm{O}_{2}$ uptake was less depressed in the amino acid-treated patients, reflecting an 'endogenous thermogenesis'. Thus, 70-80 \% of the reduction in whole-body heat content was prevented during anaesthesia in the amino acid-treated group (Fig. 1). At awakening from anaesthesia, a marked stimulation of whole-body $\mathrm{O}_{2}$ uptake occurred and the resulting heat generation almost restored body temperature to its pre-anaesthesia level within minutes, withoutshivering. In the controls body temperature and $\mathrm{O}_{2}$ uptake remained low, despite shivering. Calculations of energy expenditure from these data showed that the thermic 


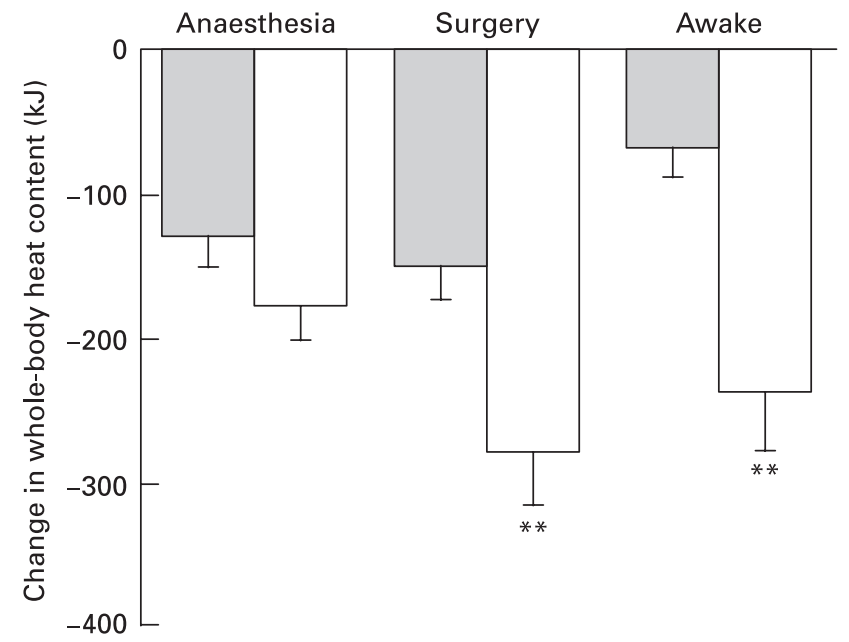

Fig. 1. Changes in whole-body heat content from baseline during anaesthesia, surgery and at awakening, calculated according to Minard (1970), for surgical patients receiving a balanced amino acid solution intravenously (-) and controls subjected to similar surgical procedures $(\square)$. Values are means with their standard errors represented by vertical bars. Mean values were significantly different from those for the treatment group: ${ }^{* \star} P<0 \cdot 01$. (From Selldén, 1998.)

effect of amino acids was enhanced fivefold during anaesthesia compared with the awake state (Selldén et al. 1994, 1996).

Amino acids were also able to stimulate metabolic heat production during general anaesthesia with muscle relaxation. It is not immediately apparent why the thermic effect of amino acids should be augmented during anaesthesia. However, it might be explained on the basis of involvement of central thermoregulation. Anaesthesia depresses metabolic rate, which results in hypothermia. Temperature control is changed, as central thermoregulation is impaired and efferent signals from the brain are largely abolished.
This process is similar to the situation in the patient with spinal injury, with disrupted nervous pathways between the brain and the periphery. In the patient with spinal injury, intravenous amino acid infusion resulted in enhanced body temperatures as compared with the normal subject (Aksnes et al. 1995). The finding of a normal, or even supranormal, NIT in the patient with spinal injury indicated that it occurred primarily in peripheral tissues, and that a central temperature-regulating inhibitory mechanism may have been eliminated. The existence of such an inhibitory action associated with central thermosensors is supported by the findings of several studies (Downey et al. 1964; Eisenman, 1974; Brundin et al. 1992), and is considered necessary to keep peripheral cellular oxidation and heat production within acceptable limits, in order to prevent hyperthermia. In conformity with the findings for the patient with spinal injury, thermogenesis in response to intravenous amino acids also occurred during general anaesthesia.

The enhanced amino acid-induced oxidative metabolism and heat production found during anaesthesia thus supports the existence of a central inhibitory temperature-regulating mechanism depressed by anaesthesia. At awakening from anaesthesia hypothalamic thermosensors are also 'awakened' and record a blood temperature below a set point. This process causes both continued blockade of inhibitory signals in order to increase the metabolic rate, and also efferent signals with increased sympathetic activity resulting in a higher metabolic rate. The synergistic action of the still uninhibited amino acid-induced thermogenesis, together with direct sympathetic stimulation, most probably explains the overshoot in metabolic rate that occurred in amino acid-treated patients at awakening.

In the awake state splanchnic and extra-splanchnic thermogenesis in response to amino acid infusion each accounts for $50 \%$ (Brundin \& Wahren, 1994). This response was shown to be different during and after anaesthesia, i.e. that extra-splanchnic heat production dominated (Selldén et al. 1996; see Fig. 2). Extra-splanchnic tissues

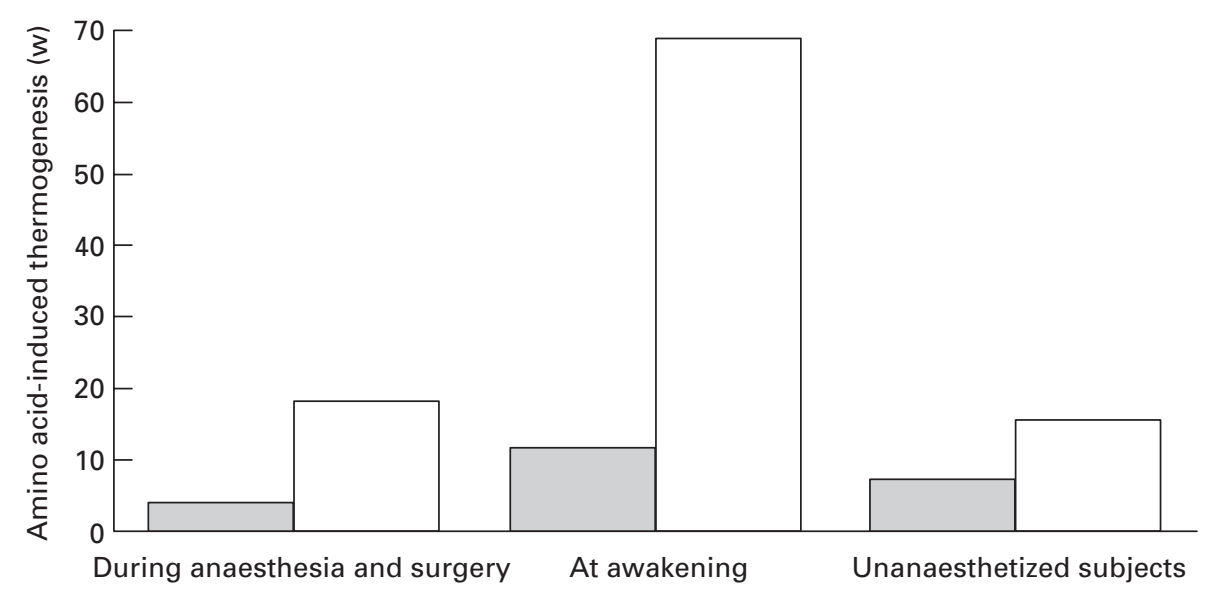

Fig. 2. Amino acid-induced thermogenesis in the whole body $(\square)$ and the splanchnic region ( expressed as the difference in mean changes from baseline heat production (W) between amino acid-treated (balanced amino acid solution intravenously) and control patients during and after anaesthesia and surgery. For comparison amino acid-induced thermogenesis in unanaesthetized individuals after 135min of identical amino acid infusion (from Brundin \& Wahren, 1994) is also shown. 
capable of great variations in $\mathrm{O}_{2}$ consumption, in addition to skeletal muscles, are the heart, brain and kidneys. Heart activity did not increase during anaesthesia, until on emergence from anaesthesia when it might have contributed, to some extent, to the enhanced metabolic rate. The brain, capable of considerable variations in $\mathrm{O}_{2}$ consumption, prefers carbohydrates as fuel for oxidation, which should have markedly increased the RER; this was not the case. The kidneys are known not to make a major contribution to amino acid-induced thermogenesis in unanaesthetized subjects, and therefore most probably are not important heat producers during anaesthesia. Based on these factors, it is not likely that the extra-splanchnic heat production occurs in the heart, brain or kidneys. It may be suggested that the skeletal muscle is, at least in part, responsible for this heat production.

Skeletal musculature is able to accommodate a large protein turnover, and may meet energy requirements by increased oxidation of fat or, perhaps, of amino acids present in excess. In fact, the present data do not allow an evaluation of whether protein synthesis or breakdown is the dominating mechanism in the metabolic response to amino acids. Both these processes are energy consuming and require extra synthesis of ATP, thus necessitating increased oxidative metabolism, resulting in increased heat production. Usually, during and after surgery, protein synthesis is decreased, and there is an amino acid flux from skeletal muscle to the liver (Felig, 1975). Infusion of single amino acids has been found to elicit considerably lower extra-splanchnic thermogenesis than that induced by a mixture of amino acids. Consequently, it seems that a balanced mixture is required for complete amino acidinduced thermogenesis. This observation may suggest that substrates were provided for, for example, protein synthesis, and thus explain part of the heat production. Protein synthesis in skeletal muscle is reported to be stimulated by availability of amino acids in excess (Svanberg et al. 1996).

In this context it might be suggested that the increased thermic effect of amino acids described during sepsis and injury (Giovannini et al. 1988) may be the result of increased use of sedative anaesthetic drugs in this category of patients. On the other hand, no thermic effect or change in substrate handling was seen when amino acids were infused at very low rate but similar total doses (Hersio et al. 1991). There was a change, however, after cardiac surgery using high-opioid anaesthesia, which itself could possibly be associated with a thermic response.

The exaggerated non-shivering thermogenesis during anaesthesia suggests the existence of a local mechanism independent of central sympathetic nervous system activation. Obviously, the previously described UCP in skeletal muscle may exert an uncoupling mitochondrial effect, resulting in heat production, or is there another second messenger as well?

This is an important area for future research in the field of thermogenesis, and may, together with inhibited central control of the metabolic rate discussed previously, also have implications for the hitherto unexplained condition of malignant hyperthermia triggered by some anaesthetic agents.

\section{Post-operative effects and outcome}

$\mathrm{N}$ excretion was studied before, during and after abdominal surgery in order to examine the effect of peri-operative amino acid infusion on post-operative recovery. Along with the reduced BMR due to anaesthetic agents, a N-sparing effect was observed in our control patients. This sparing effect was normalized when metabolic rate increased due to amino acid infusion, even during anaesthesia (Selldén \& Lindahl, 1998). This process may reflect reduced protein wasting from skeletal muscle for the synthesis of proteins needed for, for example, wound healing, immunological competence and vital organ function, thereby preserving skeletal muscle function in the early post-operative phase. It was of interest, therefore, to investigate whether this unchanged $\mathrm{N}$ excretion, indicating a normalization of $\mathrm{N}$ balance, interferes with outcome. First, it was clearly demonstrated that core body temperature was normalized at awakening from general anaesthesia. Based on information from other publications, it is known that normothermia prevents various major post-operative complications (Kurz et al. 1996; Frank et al. 1997). Second, there was no doubt that amino acid infusions reduced the incidence of postoperative shivering. The present view, that shivering is an inefficient 'heater' after anaesthesia (Frank et al. 1995), was demonstrated in our control patients, who had a low $\mathrm{O}_{2}$ consumption and were hypothermic at awakening despite shivering. Thus, the absence of shivering evidently does not interfere to any extent with temperature balance. However, shivering per se is associated with impaired quality of care, increased use of medication and pain. The question is: does a skeletal muscle that has not been subjected to shivering function better than a muscle that has been shivering, and hence speeds up mobilization of patients and reduces the length of hospital stay?

In conformity with this reasoning amino acid-treated patients had a shorter hospital stay (Selldén \& Lindahl, 1999). This finding is in agreement with those of Kurz et al. (1996), who showed that higher body temperatures after colo-rectal surgery, achieved by external heating, not only reduced the incidence of wound infection, but also resulted in a shorter hospitalization period. It is well known that external warming with forced-air warming blankets also eliminates shivering. Again, a factor that may prove to be of great importance for mobilization after surgery.

\section{Amino acids during surgery: why?}

It seems likely that, in addition to hypothermia prevention, amino acid administration to patients during anaesthesia and surgery also exerts long-term beneficial effects, as reflected by shorter convalescence. The mechanism whereby amino acid-induced thermogenesis is enhanced during anaesthesia is not, however, understood. It is of interest to investigate which method of hypothermia prevention is qualitatively superior; is it exogenous heat supply or 'endogenous' increased heat production from amino acids? When comparing the methods, variables such as the patient's thermal comfort, well-being, pain, mobilization, bowel function etc. post-operatively are all important. 
However positive it may be to reduce post-operative hypothermia, the increased $\mathrm{O}_{2}$ consumption in the amino acid-treated patients reflects the existence of a potential side effect, particularly in the cardiac patient with compromised coronary circulation. In fact, whole-body $\mathrm{O}_{2}$ uptake was increased by up to $70 \%$ at awakening from anaesthesia as compared with control patients. Whether this demand for $\mathrm{O}_{2}$ is too high for a patient with coronary disease remains to be tested. In preliminary studies, however, we have shown that amino acid infusion during cardiac bypass surgery is well tolerated by the patients (Selldén et al. 2000).

Certainly, in patients with impaired hepatic and/or renal function, amino acid infusions constitute a metabolic risk and should be avoided or given with caution. Furthermore, the appropriate amino acid solution and dose for pediatric use remains to be tested. Otherwise, amino acid treatment during anaesthesia and surgery seems to be safe and efficient for the prevention of hypothermia and its negative post-operative consequences.

\section{References}

Aksnes A-K, Brundin T, Hjeltnes N, Maehlum S \& Wahren J (1993) Meal-induced rise in resting energy expenditure in patients with complete cervical spinal cord lesions. Paraplegia 31, 462-472.

Aksnes A-K, Brundin T, Hjeltnes N \& Wahren J (1994) Glucoseinduced thermogenesis in tetraplegic patients with low sympatho-adrenal activity. American Journal of Physiology 266, E161-E170.

Aksnes A-K, Brundin T \& Wahren J (1995) Metabolic, thermal and circulatory effects of intravenous infusion of amino acids in tetraplegic patients with complete spinal cord lesions. Clinical Physiology 15, 377-396.

Berne C, Fagius J \& Niklasson F (1989) Sympathetic response to oral carbohydrate administration. Evidence from microelectrode recordings. Journal of Clinical Investigation 84, 1403-1409.

Brismar B, Hedenstierna G, Lundh R \& Tocics L (1982) Oxygen uptake, plasma catecholamines and cardiac output during neurolept-nitrous oxide and halothane anaesthesias. Acta Anaesthesiologica Scandinavica 26, 541-549.

Brundin T (1997) Glucose versus amino acids: splanchnic and total VO2 and blood flow. In Physiology, Stress and Malnutrition: Functional Correlates, Nutritional Intervention, pp. 251-274 [JM Kinney and HN Tucker, editors]. New York: Lippincott-Raven.

Brundin T (1998) Whole body and splanchnic metabolic, circulatory, and thermal effects of oral vs. intravenous fat administration. American Journal of Physiology 274, E684-E691.

Brundin T, Thörne A \& Wahren J (1992) Heat leakage across the abdominal wall and meal-induced thermogenesis in normalweight and obese subjects. Metabolism 41, 49-55.

Brundin T \& Wahren J (1994) Changes in splanchnic and wholebody oxygen consumption, blood flow and blood temperature in response to intravenous administration of amino acids. American Journal of Physiology 266, E396-E402.

Clark M, Colquhoun E, Rattigan S, Dora K, Eldershaw T, Hall J \& Ye J-M (1995) Vascular and endocrine control of muscle metabolism. American Journal of Physiology 268, E797-E812.

Downey JA, Mottram RF \& Pickering GW (1964) The location by regional cooling of central temperature receptors in the conscious rabbit. American Journal of Physiology 170, 415-441.

Eisenman JS (1974) Depression of preoptic thermosensitivity by bacterial pyrogen in rabbits. Journal of Applied Physiology 227, $1067-1073$.
Essén P, McNurlan M, Sonnenfeldt T, Milne E, Vinnars E, Wernerman J \& Garlick P (1993) Muscle protein synthesis after operation: effects of intravenous nutrition. European Journal of Surgery 159, 195-200.

Fagius J \& Berne C (1994) Increase in muscle nerve sympathetic activity in humans after food intake. Clinical Science 86, 159-167.

Felig P (1975) Amino acid metabolism in man. Annual Review of Biochemistry 44, 933-955.

Frank S, Fleisher L, Breslow M, Higgins M, Olsson K, Kelly S \& Beattie C (1997) Perioperative maintenance of normothermia reduces the incidence of morbid cardiac events: a randomized clinical trial. Journal of the American Medical Association 277, 1127-1134.

Frank SM, Fleisher LA, Olson KF, Gorman RB, Higgins MS, Breslow M, Sitzman JV \& Beattle C (1995) Multivariate determinates of early postoperative oxygen consumption: the effects of shivering, core temperature, and gender. Anesthesiology 83, 241-249.

Giovannini I, Chiarla C, Boldrini G, Castiglioni GC \& Castagneto M (1988) Calorimetric response to amino acid infusion in sepsis and critical illness. Critical Care Medicine 16, 667-670.

Hammarqvist F, Wernerman J, Ali R, von der Decken A \& Vinnars E (1989) Addition of glutamine to total parenteral nutrition after elective abdominal surgery spares free glutamine in muscle, counteracts the fall in muscle protein synthesis, and improves nitrogen balance. Annals of Surgery 209, 455-461.

Hersio K, Takala J, Kari A \& Huttunen H (1991) Changes in whole body and tissue oxygen consumption during recovery from hypothermia: effect of amino acid infusion. Critical Care Medicine 19, 503-508.

Horwath S, Sparr G, Hutt B \& Hamilton L (1956) Metabolic cost of shivering. Journal of Applied Physiology 8, 595-602.

Jéquier E (1986) The influence of nutrient administration on energy expenditure in man. Clinical Nutrition 5, 181-186.

Jezek P \& Garlid KD (1998) Mammalian mitochondrial uncoupling proteins. International Journal of Biochemistry and Cellullar Biology 30, 1163-1168.

Joris J, Ozaki M, Sessler DI, Hardy AF, Lamy M, McGuire J, Blanchard D, Schroeder M \& Moayeri A (1994) Epidural anesthesia impairs both central and peripheral thermoregulatory control during general anesthesia. Anesthesiology 80, 268-277.

Kurz A, Sessler DI \& Lenhardt R (1996) Perioperative normothermia to reduce the incidence of surgical-wound infection and shorten hospitalization. New England Journal of Medicine 334, 1209-1215.

Kurz A, Sessler DI \& Narzt E (1995) Postoperative hemodynamic and thermoregulatory consequences of intraoperative core hypothermia. Journal of Clinical Anesthesia 7, 359-366.

Landsberg L \& Young JB (1978) Fasting, feeding and regulation of the sympathetic nervous system. New England Journal of Medicine 298, 1295-1301.

Leslie K \& Solly M (1995) Brain protection during neurosurgery: an update from the anesthetist's perspective. Journal of Clinical Neuroscience 2, 285-294.

Lowell BB \& Spiegelman BM (2000) Towards a molecular understanding of adaptive thermogenesis. Nature 404, 652-660.

Mao W, Yu XX, Zhong A, Li W, Brush J, Sherwood SW, Adams SH \& Pan G (1999) UCP4, a novel brain-specific mitochondrial protein that reduces membrane potential in mammalian cells. FEBS Letters 443, 326-330.

Minard D (1970) Body heat content. In Physiological and Behavioral Temperature Regulation, pp. 345-357. [JD Hardy, AP Gagge and JA Stolwijk, editors]. Springfield, IL: Charles C Thomas.

Nedergaard J \& Cannon B (1998) Brown adipose tissue: development and function. In Fetal and Neonatal Physiology, 
pp. 478-489 [R Polin and W Fox, editors]. Philadelphia, PA WB Saunders.

Neumann RA (1902) Experimentelle Beiträge zur Lehre von dem täglichen Nahrungsbedarf des Menschen unter besonderer Berucksichtigung der notwendigen Eiweissmenge (Experimental contributions to the assignment of the daily food requirement of man, with particular consideration of the necessary quantity of eggwhite). Archives des Hygiene und Bakteriologie 45, 1-87.

Newsholme EA, Crabtree B \& Parry-Billings M (1992) The energetic cost of regulation: An analysis based on the principles of metabolic-control-logic. In Energy Metabolism: Tissue Determinants and Cellullar Corollaries, pp. 467-493 [JM Kinney and HN Tucker, editors]. New York: Raven Press.

Ohlson K, Mohell N, Cannon B, Lindahl S \& Nedergaard J (1994) Thermogenesis in brown adipocytes is inhibited by volatile anesthetic agents. Anesthesiology 81, 176-183.

Rubner M (1902) Die Gesetze des Energieverbrauchs bei der Ernährung (The Regulation of Energy Expenditure during Nutrient Intake), [E Deuticker, editor]. Leipzig: Leibzig \& Wienna.

Selldén E (1998) Amino acid induced thermogenesis during anaesthesia. PhD Thesis, Karolinska Institute, Stockholm, Sweden.

Selldén E, Bränström R \& Brundin T (1996) Augmented thermic effect of amino acids under general anaesthesia occurs predominantly in extra-splanchnic tissues. Clinical Science 91, 431-439.

Selldén E, Brundin T \& Wahren J (1994) Augmented thermic effect of amino acids under general anaesthesia: a mechanism useful for prevention of anaesthesia-induced hypothermia. Clinical Science 86, 611-618.

Selldén E \& Lindahl SGE (1998) Postoperative nitrogen excretion after amino acid-induced thermogenesis under anaesthesia. Anesthesia and Analgesia 87, 641-646.

Selldén E \& Lindahl SGE (1999) Amino acid-induced thermogenesis reduces hypothermia during anaesthesia and shortens hospital stay. Anesthesia and Analgesia 89, 916-922.

Selldén E, Rimeika D, Lindahl SGE \& Settergren G (2000) Amino acid-induced thermogenesis during cardiac by-pass surgery - no effect on extubation time. Clinical Nutrition 19, 22.

Svanberg E, Möller-Loswick A-C, Matthews D, Körner U, Andersson M \& Lundholm K (1996) Effects of amino acids on synthesis and degradation of skeletal muscle proteins in humans. American Journal of Physiology 271, E718-E724.

Theye RA \& Michenfelder JD (1975) Whole body and organ VO2 changes with enflurane, isoflurane and halothane. British Journal of Anaesthesia 47, 813-817.

Thorell A, Nygren J \& Ljungkvist O (1999) Insulin resistance: a marker of surgical stress. Current Opinion in Clinical Nutrition and Metabolic Care 2, 69-78.

Vaughan MS, Vaughan RW \& Cork RC (1981) Postoperative hypothermia in adults; Relationship of age, anaesthesia, and shivering to rewarming. Anesthesia and Analgesia 60, 746-751.

Welle SL, Lilavivat U \& Campbell RG (1981) Thermic effect of feeding in man. Increased plasma norepinephrine levels following glucose but not protein or fat consumption. Metabolism 30, 953-958. 